\title{
PEMODELAN LATAR BELAKANG ADAPTIF MENGGUNAKAN METODE GAUSSIAN MIXTURE MODEL PADA VIDEO DALAM AIR
}

\author{
Hudayani Nurul ${ }^{1}$, S. R. Sulistiyanti ${ }^{2}$, F. X. Arinto $S^{3}$ \\ Jurusan Teknik Elektro Universitas Lampung \\ J1. Prof. Sumantri Brojonegoro No.1 Bandar Lampung 35145 \\ ${ }^{1}$ Nurul. hudayaniestudents.unila.ac.id \\ ${ }^{2}$ sr_sulistiyanti@eng.unila.ac.id \\ ${ }^{3}$ fx.arintodeng.unila.ac.id
}

Intisari - Aplikasi teknik pengolahan citra sudah digunakan dalam berbagai bidang kehidupan salah satunya adalah untuk proses deteksi objek. Salah satu tahap pada proses deteksi objek adalah pemodelan latar balakang. Pada penelitian ini dibuat suatu program yang dapat dugunakan untuk memodelkan latar belakang adaptif pada video dalam air menggunakan metode Gaussian Mixture Model dengan sofware Visual Studio 2010 dan Library OpenCV.Proses pada pemodelan ini adalah subtraksi model latar belakang awal dengan frame pertama yang hasilnya akan digunakan untuk mengupdate model latar belakang, begitu seterusnya hingga pada frame terakhir. Proses subtraksi dan updating dilakukan pada masing-masing intensitas piksel pada frame tersebut. Hasil pada penelitian untuk menentukan nilai $\beta$ dan $\rho$ terbaik yang nanti akan digunakan untuk proses deteksi objek. Efektifitas dari metode ini dinyatakan dengan nilai PSNR, dimana pada tiga kondisi video (pagi, siang dan malam) menunjukan nilai PSNR yang berbeda-beda yaitu 69,87 dB, 66,01 dB, dan $36,58 \mathrm{~dB}$.

Kata kunci : Pemodelan latar belakang, Gaussian mixture model, Visual studio.

\section{PENDAHULUAN}

Saat ini teknik pengolahan citra banyak digunakan untuk sistem keamanan maupun sistem pemantauan (monitoring). Fungsi pemantauan telah banyak dilakukan di darat, tetapi untuk objek dalam air belum banyak dilakukan. Teknik deteksi objek terbagi dalam beberapa kategori yaitu Point Detector, Segmentation, Background Modelling, dan Supervised Classifer [1]. Salah satu fungsinya adalah untuk memonitoring jumlah objek yang ada disekitar kamera. Kamera di sini digunakan untuk menggantikan mata manusia untuk mengawasi objek di dalam air. Pada aplikasi ini dilakukan dengan cara memisahkan antara latar belakang dengan objek yang bukan merupakan bagian dari latar belakang. Piksel daerah yang mengalami perbedaan akan ditandai untuk pemrosesan lebih lanjut proses ini disebut background subtraction [2]. Objek dalam hal ini adalah ikan.

Pembedaan antara latar belakang dan objek didalam air tentu tidak mudah dilakukan karena terdapat banyak gangguan seperti ketidakpastian intensitas cahaya yang masuk dan juga karena gerakan air. Gangguan ini dapat mempengaruhi hasil identifikasi. Penggunaan citra sekuensial ditujukan untuk mendapatkan nilai toleransi terhadap perubahan pencahayaan yang mungkin terjadi pada saat pengambilan latar belakang [3]. Oleh karena itu perlu adanya pemodelan latar belakang yang dapat beradaptasi dengan baik sehingga dapat memisahkan antara latar belakang dengan objek serta tidak mendeteksi perubahan gerakan air dan intensitas cahaya sebagai objek [4]. 
Terdapat beberapa kendala dalam penggunakan metode background subtraction seperti peralihan pencahayaan dan juga bayangan dari objek [4] oleh karena itu terdapat beberapa penelitian untuk mengatasi masalah tersebut. Li (2003) yang mengusulkan metode berbasis Bayes untuk mendeteksi dan segmentasi objek dari latar belakang statis dan dinamis [5]. Arif (2012) menggunakan algoritma Fuzzy C-Mean untuk menentukan nilai ambang adaptif untuk proses segmentasi [6]. Otsu Maddalena (2012) mengajukan teknik pengurangan latar belakang dengan algoritma Neural Network Self Organizing Map (SOM) yang digunakan untuk memisahkan antara pixel latar belakang dengan objeknya untuk area surveillance [7]. Davis (2004) mengajukan sebuah algoritma Codebooks yang digunakan kompresi background untuk mempelajari variasi sturktur background dalam jangka waktu yang panjang dan jumlah memory terbatas [8]. Stauffer dan Grimsom (1999) mengusulkan metode Gaussian Mixture Model (GMM) [9][10]. Penggunaan metode Gaussian Mixture model juga dilakukan untuk menghilangkan bayangan objek agar tidak ikut terdeteksi [11][12].

Penelitian ini menggunakan latar belakang adaptif yang bekerja dengan memperhitungkan nilai pixel dari semua frame yang berurutan. Akan tetapi latar belakang adaptif kurang efisien apabila input yang akan dideteksi terlalu banyak dan gangguan yang sebenarnya adalah latar belakang besar sehingga perlu menggunakan metode Gaussian Mixture Models (GMM).

\section{METODE YANG DIUSULKAN}

Video diambil menggunakan kamera statik bawah air dimana latar belakang selalu berubah. Perubahan ini disebabkan oleh gerakan gelombang air dan juga intensitas cahaya yang diterima.

\section{A. Pengolahan Awal}

Pengolahan awal pada metode ini adalah inisialisasi distribusi normal yaitu menginisialisasi nilai mean dan variant awal yang akan digunakan. Pada penelitian ini frame pertama pada masing-masing video digunakan langsung sebagai nilai mean (model latar belakang awal). Sebelum digunakan sebagai inisialiasasi awal, frame tersebut diubah menjadi grayscale untuk mempermudah komputasi. gambar 1 merupakan hasil hasil inisialisasi distribusi normal untuk masing-masing kondisi

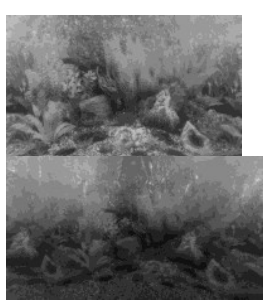

(a)

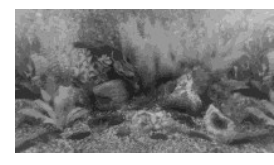

(b)

(c)
Gbr 1. Hasil pengolahan awal (a) kondisi pagi hari (b) kondisi siang hari (c) kondisi malam hari)

Sedangkan untuk nilai variant awal yang digunakan pada penelitian ini adalah sebuah matrik yang bernilai 1 .

\section{B. Hasil Perbandingan Dua Buah Frame}

Proses perbandingan dilakukan terus menerus antara model latar belakang dengan frame selanjutnya. Perbandingan ini dilakukan dengan cara mengurangkan model latar belakang dengan frame selanjutnya menggunakan nilai batas ambang. Nilai batas ambang didapatkan dari hasil perkalian threshold dengan variant. Threshold bernilai tetap yaitu 30 sedangkan variant nilainya diperbaharui. Hasil perbandingan dua buah frame ini digunakan untuk mengetahui perbedaan nilai antara model latar belakang dengan frame selanjutnya.Gambar 2 menunjukan hasil perbandingan model latar belakang ke 29 dengan frame ke 30 pada masing-masing kondisi

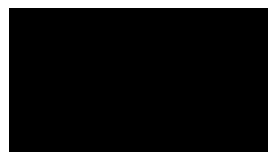

(a)

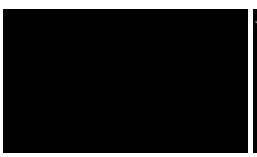

(b)

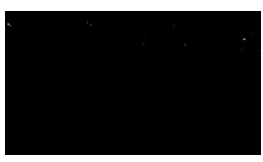

(c)
Gbr. 2 Hasil pengurangan dua buah frame (a) kondisi pagi hari (b) kondisi siang hari (c) kondisi malam hari 
Nilai perbandingan ini akan menentukan algoritma yang akan digunakan untuk melakukan pembaharuan nilai variant dan juga mean. Hasil perbandingan yang diharapkan adalah semuanya berwarna hitam yang berarti bahwa semua pixel dianggap sebagai latar belakang.

\section{Pembaharuan Distribusi Normal.}

Model latar belakang didapatkan dari pembaharuan nilai mean dan variant saat terdapat frame baru yang masuk. Pembaharuan mean menggunakan persamaan

$$
\begin{gathered}
\mu_{T+1_{(x, y)}}= \\
\left\{* f_{t+1_{(x, y)}}+(1-\rho) * \mu_{T(x, y)}\right. \\
\text { Jika } f_{T+1_{(x, y)}}=\text { Latar Belakang } \\
(1-\beta) * f_{T+1_{(x, y)}}+\beta * \mu_{T_{(x, y)}} \\
\text { Jika } f_{T+1_{(x, y)}}=\text { Bukan Latar Belakang }
\end{gathered}
$$

Sedangkan pembaharuan untuk variant menggunakan persamaan :

$$
\sigma_{T+1_{(x, y)}}^{2}=\left\{\begin{array}{c}
\rho *\left(f_{T+1_{(x, y)}}-\mu_{T+1_{(x, y)}}\right)^{2}+(1+\rho) * \sigma_{T_{(x, y)}}^{2}, \\
\text { Jika } f_{T+1_{(x, y)}}=\text { Latar Belakang } \\
(1+\beta) *\left(f_{T+1_{(x, y)}}-\mu_{T+1_{(x, y)}}\right)^{2}+\beta * \sigma_{T_{(x, y)}}^{2}, \\
J i k a f_{T+1_{(x, y)}}=\text { Objek }
\end{array}\right.
$$

Peneliti memasukan beberapa nilai $\rho$ dan $\beta$ untuk mencari nilai $\rho$ dan $\beta$ terbaik untuk masing masing kondisi. Nilai $\rho$ dan $\beta$ yang terbaik nantinya akan digunakan untuk proses deteksi objek.

\section{HASIL PENELITIAN}

Pada penelitian ini video yang di olah terdiri dari tiga keadaan yaitu pagi siang dan malam masing-masing mempunyai durasi selama 3 detik. Video pertama yang diambil saat pagi hari dan video kedua yang diambil saat siang hari mendapatakan cahaya yang cukup dengan intensitas cahaya sebesar 525,81 lux dan 670 lux. Sedangkan pada video ketiga yang diambil saat malam hari mendapatkan pencahayaan yang sangat kurang dengan intensitas cahaya hanya 0,02 lux. Pengambilan data dilakukan menggunakan kamera aksi dengan bantuan tripod. Kamera aksi yang digunakan mempunyai resolusi 1920 x 1080. Proses pemodelan latar belakang dilakukan menggunakan komputer dengan sistem operasi Windows 10, Processor Intel Core $i 7$,menggunakan perangkat lunak Ms. Visual Studio 2010 dengan bahasa pemrograman $\mathrm{c}++$ dan Open $C v$ 2.4.13. Pembentukan model latar belakang di peroleh dari pembaharuan nilai distribusi normal piksel piksel latar belakang. Berikut adalah model latar belakang pada video dengan kondisi pagi, siang dan malam hari.

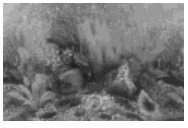

(a)

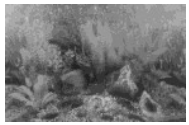

(b)

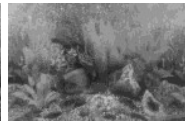

(c)

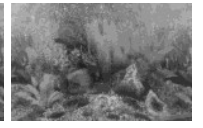

(d)
Gbr. 3 Model latar belakang pada kondisi pagi hari dengan $\rho=0,2 ; \beta=0,2$ (a) Frame ke-2 (b) Frame ke-30 (c) Frame ke-60 (d) Frame ke-90

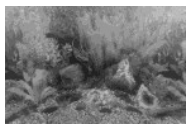

(a)

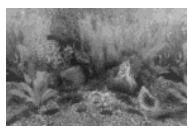

(b)

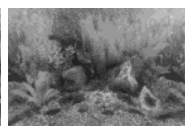

(c)

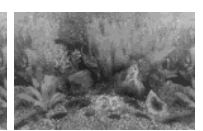

(d)
Gbr. 4 Model latar belakang pada kondisisiang hari dengan $\rho=0,8 ; \beta=0,2$ (a) Frame ke-2 (b) Frame ke-30 (c) Frame ke-60 (d) Frame ke-90

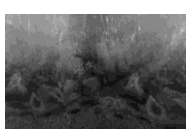

(a)

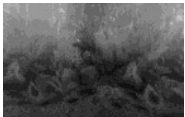

(b)

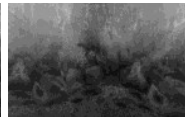

(c)

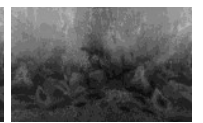

(d)
Gbr. 5 Model latar belakang pada kondisi malam hari dengan $\rho=0,6 ; \beta=0,2$ (a) Frame ke-2 (b) Frame ke-30 (c) Frame ke-60 (d) Frame ke-90

Kinerja metode dihitung menggunakan Peak Signal to Noise Ratio (PNSR) dengan menghitung jumlah pixel putih yang terdapat pada hasil pengurangan. Semakin banyak pixel putih maka nilai PSNR semakin kecil, begitu juga sebaliknya, semakin sedikit pixel putih maka nilai PSNR semakin besar [13][14].Secara matematis nilai PSNR dituliskan sebagai berikut

$$
\begin{aligned}
& \operatorname{MSE}(X, Y)=\frac{1}{M N} \sum_{i=1}^{M} \sum_{j=1}^{N}[X(i, j)- \\
& Y(i, j)]
\end{aligned}
$$




$$
\operatorname{PSNR}(X, Y)=10 \cdot \log _{10}\left(\frac{\max ^{2}}{\operatorname{MSE}(X, Y)}\right)
$$

Keterangan :

$\max ^{2}:$ Nilai pixel terbesar pada keseluruhan citra.

i dan $\mathrm{j}$ : Koordinat suatu titik pada citra.

M dan N : Dimensi dari citra.

$\mathrm{X}$ : Selisih model latar belakng dengan frame

Y : Matrik dengan nilai 0

Nilai PSNR juga digunakan untuk menentukan nilai $\rho$ dan $\beta$ yang paling baik untuk model latar belakang pada masingmasing video yaitu yang mempunyai nilai PSNR yang tertinggi. Nilai PSNR dikatakan baik apabila bernilai lebih dari $40 \mathrm{~dB}$ dan dikatakan buruk apabila bernilai kurang dari 30 dB. Pada penelitian ini nilai PSNR tertinggi adalah $70 \mathrm{~dB}$ dengan perhitungan apabila nilai $\mathrm{MSE}=0$ maka nilai PSNR diasumsikan sebesar 0,00001 dB. Hal ini dilakukan agar tidak didapatkan nilai PSNR tak terhingga.Nilai PSNR yang dihitung adalah rata-rata dari 90 frame untuk nilai $\rho$ dan $\beta$ yang berbeda-beda. Suatu metode dikatakan baik apabila mempunyai nilai MSE yang rendah dan nilai PSNR yang tinggi. Tabel 1 memperlihatkan hasil perhitungan PSNR pada pagi, siang, dan malam hari.

Sedangkan pada malam hari nilai PSNR tertinggi didapat saat $\beta$ bernilai 0,6 dan $\rho$ bernilai 0,2 dengan rata-rata $36,58 \mathrm{~dB}$. Untuk mengatahui efektrifitas metode ini, peneliti juga menggunakan metode tanpa pembaharuan untuk video yang sama. Dan berikut adalah grafik hasil perbandingan kedua metode.

Tabel 1 Hasil perhitungan PSNR yang terbaik untuk kondisi pagi hari

\begin{tabular}{|c|c|c|c|}
\hline No & $\rho$ & $\beta$ & PSNR $(\mathrm{dB})$ \\
\hline 1 & 0,2 & 0,2 & 69,87 \\
\hline 2 & 0,2 & 0,4 & 69,87 \\
\hline 3 & 0,2 & 0,6 & 69,87 \\
\hline 4 & 0,2 & 0,8 & 69,87 \\
\hline
\end{tabular}

Tabel 2 Hasil perhitungan PSNR yang terbaik untuk kondisi siang hari

\begin{tabular}{|c|c|c|c|}
\hline No & $\rho$ & B & PSNR (dB) \\
\hline 1 & 0,8 & 0,2 & 66,01 \\
\hline 2 & 0,8 & 0,4 & 66,01 \\
\hline 3 & 0,8 & 0,6 & 66,01 \\
\hline
\end{tabular}

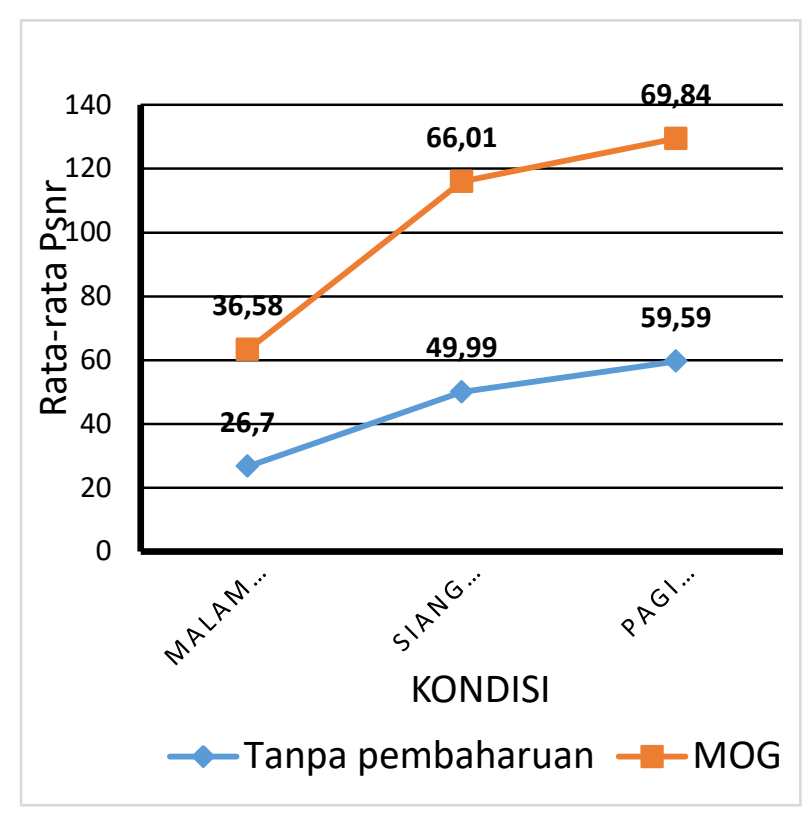

Gbr. 6 Grafik Hasil perbandingan rata-rata PSNR metode GMM dan metode tanpa pembaharuan

Pada gambar 6 menunjukan bahwa nilai yang dihasilkan pada metode GMM lebih tinggi dibandingkan pada metode pembanding. Hal ini menunjukan bahwa metode GMM baik untuk proses pemodelan latar belakang.

\section{KESIMPULAN}

Metode GMM digunakan untuk memodelkan latar belakang yang baik untuk video dalam air yang dapat meminimalisir perubahan nilai piksel yang minim sehingga nilai piksel tersebut tidak dianggap sebagai objek. Pada peneilitian ini menunjukan bahwa metode GMM berhasil memodelkan latar belakang adaptif Pada malam hari, ratarata nilai PSNR terendah dibandingkan dengan pagi dan siang hari hal ini dikarenakan pencahayaan pada malam hari 
tidak stabil sehingga mengganggu model latar belakang yang ada.

Metode GMM baik untuk digunakan dalam pemodelan latar belakang dibandingkan dengan pemodelan tanpa pembaharuan.Dan untuk nilai PSNR pada setiap video selalu berbeda-beda hal ini dipengaruhi oleh kualitas video dan juga nilai $\beta$ dan $\rho$ yang diberikan.

\section{REFERENSI}

[1] Yilmaz A, dkk. 2006. Object Tracking. ACM international conference Vol. 38, no. 4, pp 13.

[2] Wahyudi Noor, dkk. 2015. Background Subtraction Berbasis Self Organizing Map untuk Deteksi Objek Bergerak Systemic. Vol. 1. No. 1. Pp 42-51.

[3] R.E Binarahandra. 2014. Subtraksi Background dan Deteksi Bayangan pada Citra Grayscale Sekuensial. Laporan Tugas Akhir. Jurusan Teknik Informatika, Universitas Kristen Duta Wacana, Yogyakarta

[4] Rostianingsih Silvia, dkk. 2012. Adaptive Background dengan Metode Gaussian Mixture Model untuk RealTime Tracking. Laporan Tugas Akhir. Jurusan Teknik Informatika, Fakulas Teknologi Industri, Universitas Kristen Petra, Surabaya

[5] Li L, dkk. 2003. Foreground object detection from videos containing complex background. Proceedings of the eleventh ACM international conference on Multimedia. Vol. 03. p. 2.

[6] Soeleman M. A, dkk. 2012. Adaptive threshold for background subtraction in moving object detection using Fuzzy C-Means clustering. TENCON 2012 IEEE Region 10 Conference. pp. 1-5.

[7] L. Maddalena and A. Petrosino. 2008. "A self- organizing approach to background subtraction for visual surveillance applications.," IEEE transactions on image processing: a publication of the IEEE Signal Processing Society, Vol. 17. no. 7. pp. 1168-77.
[8] Chalidabhongse T. H, dkk. 2004. Background modeling and subtraction by codebook construction. International Conference on Image Processing. ICIP vol. 5. pp. 3061-3064.

[9] Johann P. Wayne Power. 2002. Understanding Background Mixture Models for Foreground Segmentation Industrial Research Limited. Proceedings Image and Vision Computing New Zealand, University of Auckland, Auckland, New Zealand.

[10] Stauffer C., Grimson W.E.L. Grimson. 1999. Adaptive Background Mixture Models for Real-Time Tracking.

[11] Ismahyudi, dkk. 2013. Pelacakan Kendaraan Bermotor di Jalan Tol Semarang Menggunakan Kalman Filter dan Mixture of Gaussian dengan Video Kualitas Rendah. Seminar Teknologi Informasi dan Komunikasi Terapan. Program Pasca Sarjana, Universitas Dian Nuswantoro, Semarang.

[12] Pong P Kaew Tra Kul and Bowden R. 2011. An Improved Adaptive Background Mixture Model for Realtime Tracking with Shadow Detection. In Proc 2nd European Workshop on Advanced Video Based Surveillance Systems, AVBS01. Vision and Virtual Reality group, Department of Systems Engineering, Brunel University.

[13] Ibrahim H. 2012. Adaptive Switching Median Filter Utilizing Quantized Window Size to Remove Impulse Noise from Digital Images. Asian Transactions on Fundamentals of Electronics, Communication \& Multimedia, vol. 02, no. 01, pp. 1-6.

[14] A. A. Patil and J. Singhai. 2010. Image denoising using curvelet transform: an approach for edge preservation. vol. 69. no. Januari. pp. 34-38. 